\title{
Plastic Packaging Waste Segregation Behavior of Residents and its Environmental Effect on Municipal Solid Waste Management
}

\author{
Tomohiro Tabata $^{a *}$, Minori Oda ${ }^{a}$, Peii Tsai $^{b}$, Keiko Katagiri $^{a}$ \\ ${ }^{a}$ Kobe University, Kobe, Japan \\ ${ }^{b}$ Yokohama City University, Yokohama, Japan
}

\begin{abstract}
This study surveyed the plastic packaging waste segregation behavior of residents of Kobe, Japan, especially aged residents. It discusses the possible environmental effects on the municipal solid waste management system that could occur due to the projected increase in the number of senior citizens in the population and the consequent changes in garbage segregation behavior. Two questionnaire surveys of 1,653 people aged 20 to 99 years old residing in Kobe, Japan, were conducted. The results revealed that younger age groups have a low level of plastic waste segregation behavior despite a high level of recognition that plastic packaging waste is recyclable. We also found that the level of segregation increases among older age groups but that the level decreases among residents of 85 years and older because of diminished physical mobility. Based on the result, we discuss education about the existing rules pertaining to garbage segregation by using a quantification of the $\mathrm{CO}_{2}$ emissions avoided and not avoided by waste segregation.
\end{abstract}

Keywords: Aging Rate, Garbage Segregation Behavior, Plastic Packaging Waste, Municipal Solid Waste Management

\section{Introduction}

Incineration processes emit more $\mathrm{CO}_{2}$ than do material recovery processes, as determined by using life cycle assessment (LCA) [1]. Recycling the recyclable portion of combustible waste decreases the amount of incineration, thus reducing $\mathrm{CO}_{2}$ emissions from the incineration process. As proper segregation is considered a prerequisite for municipal Solid Waste (MSW) recycling, it is important to understand household waste segregation behavior in order to improve the recycling rate.

Garbage segregation behavior could change according to the structure of a population. As an example, the aging rate and the increase of the senior age segment (65 and older) within the population have been increasing in Japan. The Cabinet Office of Japan [2] forecasts that the proportion of the senior age segment will increase to $38.1 \%$ in 2060 from $27.3 \%$ in 2016. Japan's aging rate is by far the highest in the world, and the increase in social security costs is a major concern.

However, there are other problems associated with an aging population, and one of the services that might be affected by an

${ }^{*}$ Corresponding author. Tel.: +81788037887

Fax:+81788037887; E-mail: tabata@people.kobe-u.ac.jp

(C) 2018 International Association for Sharing Knowledge and Sustainability

DOI: $10.5383 /$ ijtee. 16.02 .002 increase in the aging rate is garbage collection and treatment by local municipalities. It is expected that senior citizens with disabilities or cognitive decline might have difficulties in following the guidelines of garbage collection issued by local governments.

Another issue, the changing composition of the households in which senior citizens reside, also affects garbage collection. In Japan, the proportion of senior citizens living alone or with another senior citizens was $56.9 \%$ in 2015 [2]. Thus, more than $71.8 \%$ of these senior citizens lived with younger family members who were responsible for garbage segregation and bringing garbage bags to the collection station in 1980 . However, this proportion changed to $43.1 \%$ in 2015 , so it became more for senior citizens to be independent at performing the segregation task. In addition, the policy of the Japanese government regarding medical care and nursing care for senior citizens has changed according to newly enacted law [2]. Due to this policy change, elderly care has been shifted from facility care to home care, which is beneficial for senior citizens who may wish to continue living in their home. Nevertheless, some senior citizens who have disabilities and/or mild cognitive impairment cannot receive nursing care services at a facility due to the policy changes. They must receive nursing care at home. 
Many local municipalities offer garbage segregation and collection for these citizens. Nonetheless, such services are at risk of continuation if the proportion of senior citizens increases. These aforementioned issues might affect the dynamics of garbage collection and treatment services offered by local governments. Residents of Japan participate in garbage collection and management systems by washing and segregating recyclables. However, due to the aging of the population, the number of people who are unable to segregate their garbage sufficiently is likely to increase.

This study aimed to survey the plastic packaging waste segregation behavior of inhabitants of Japan, especially senior citizens, and evaluate the environmental effect on the MSW management system considering the expected increase in senior citizens within the population and the impact of this increase on garbage segregation behavior.

Previous studies have examined household waste segregation behavior. For example, Secondi et al. [3] evaluated the reduction and segregation of food waste in EU-27 countries. Vencatasawmy et al. [4] and Wan et al. [5] created models to identify the factors influencing recycling behavior in Sweden and Hong Kong, respectively. In another case study in a city in Malaysia, Malika et al. [6] investigated the correlation between community participation in recycling programs and the attitude of members of the community toward waste segregation. Saeed et al. [7] discussed recyclable components based on a prediction of MSW in the future in Malaysia. Miafodzyeva et al. [8] surveyed the recycling behavior of immigrants from different parts of the world in Sweden. Matter et al. [9] revealed that waste segregation promotes accessibility for waste pickers. Bernstad [10] conducted experiments in households to investigate household waste segregation behavior. Tudor et al. [11] investigated a strategy for improving recycling behavior among employees in the UK. Matsui et al. [12] revealed that inhabitants feel increased strain with increased distance from their home to a collection station, the number of different wastes to be segregated, and so on. Yanagibori and Koyano [13] conducted a questionnaire survey to determine the attitudes of inhabitants toward waste segregation. Suzuki et al. [14] quantified the relationship between inhabitant strain and their taking out the garbage. Toshiki and $\mathrm{Yu}$ [15] described a high mixing rate of unsuitable materials despite the strict recycling system and landfilling in Korea. Regarding household waste segregation and senior citizens, Miyamae [16] revealed the relationship between aging and garbage bags that were not collected because of violations of the local municipality's segregation rule. Struk and Soukopová [17] explained that senior citizens generate more household waste and segregate less waste than younger people. Soukopová et al. [18] also revealed that senior citizens account for a larger expenditure of municipal waste collection. Unfortunately, there are few studies on trends of waste segregation behavior among people of various age groups and lifestyles, especially senior citizens.

\section{Methods}

\subsection{Background on aging in Japan}

According to Japan's population census, population has declined since 2015. The National Institute of Population and Social Security Research [19] predicts that population will continue to decline and that the aging rate will continue to increase. One of the reasons for the rapid increase in the aging rate is the increase in average life expectancy. The average life expectancy in Japan is 80.50 years for males and 86.63 years for females [20]. However, senior citizens have a wide variety of individual features. For example, although there is a distinct trend for intrinsic capacity to decline with age, there are some exceptional individuals aged 80 and older who maintain their intrinsic capacity at significantly higher levels than the mean observed in young adults [21]. On the other hand, Suzuki [22] suggested that the probability of survival starts declining at 75 years of age. Kaiduka [23] also indicated that the degree of autonomy starts declining at 70 years and that the pace of walking of people aged 75 or older is slower than that of people aged 65 to 74 years [22]. Suzuki [22] also noted that senior citizens who walk at a great speed are able to maintain their health and manage daily chores without help from others. Based on these studies, the borderline age at which people can maintain their health is approximately 75 years.

A decline in mobility caused by loss of muscle strength has several effects on the daily life of the elderly. Miyamae [16] noted a positive correlation between the number of senior citizens in a district and the volume of garbage that violates the local segregation rules. In Japan, such garbage is not collected by the local municipality. In addition, although many developed countries, including Japan, mandate their citizens to finely segregate garbage, some senior citizens find this cumbersome and physically and cognitively challenging.

\subsection{Case Study Area}

Figure 1 shows the location of the case study area. Kobe, Japan, has a population of approximately 1.54 million (2015), which is the sixth highest urban population in the country. Kobe is a part of Osaka megacity, having a population of approximately 17 million. The proportion of senior citizens in this city is $26.6 \%$, which is inline with the general proportion of Japan (26.6\%) [2, 24]. The reason that Kobe was targeted as the case study area was to provide recommendations and a roadmap for MSW management considering near future aging in neighboring cities.

\subsection{Questionnaire Survey}

Two web-based online surveys with qualified respondents living in Kobe were conducted. The first survey was conducted in the period of November 16-24, 2015, and 1,242 people aged 20-69 years responded. The second survey was conducted during June 14-17, 2016, and 413 people over 70 years old responded. In the surveys, respondents from age 20 to 70 or older answered the questions themselves. If some people under age 69 shared a

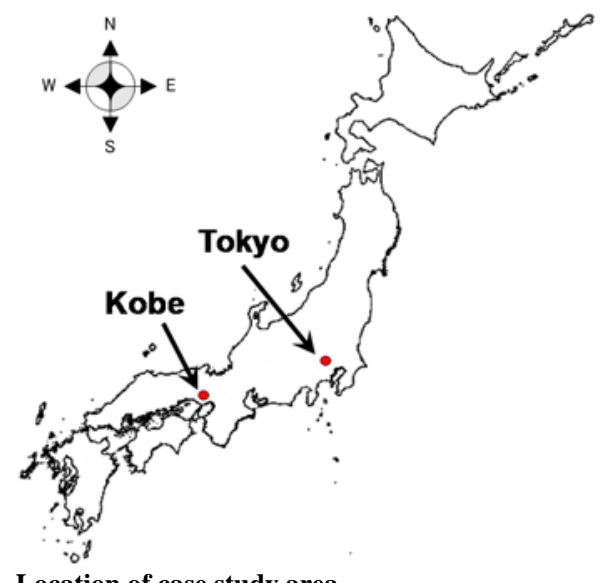

Fig. 1. Location of case study area 
Table 1. Categories of plastic packaging waste [25]

\begin{tabular}{l|c}
\hline & Weight share \\
\hline $\begin{array}{l}\text { (1) Cups, food containers and packs } \\
\begin{array}{l}\text { Ex. Cups (puddings, yogurts, ice cream and so on), food } \\
\text { containers (boxed lunches, tofu, margarine and so on) and packs } \\
\text { (eggs, vegetables, hams, sausages, retort foods and so on) }\end{array}\end{array}$ & $34 \%$ \\
\hline $\begin{array}{l}\text { (2) Packaging of product (excluding aluminum component) } \\
\text { Ex. Exterior film (snacks, noodles and so on), bags (clothes, } \\
\text { glossaries and so on) and plastic bottle labels }\end{array}$ & $27 \%$ \\
$\begin{array}{l}\text { (3) Plastic bottles (excluding polyethylene terephthalate) } \\
\text { Ex. Bottles (cooking oil, sauce, dressing, detergent, bleach, } \\
\text { shampoo, cosmetics and so on) }\end{array}$ & $17 \%$ \\
\hline $\begin{array}{l}\text { (4) Plastic bags } \\
\text { (5) Aluminum foil compound }\end{array}$ & $9 \%$ \\
$\begin{array}{l}\text { Ex. Chocolates, gum, ice cream, soap, detergents, shampoo and } \\
\text { so on }\end{array}$ & $8 \%$ \\
$\begin{array}{l}\text { (6) Packaging of delivery agents } \\
\text { Ex. Food wrap (fresh foods, boxed lunches and so on) and } \\
\text { packaging (bread, snacks, vegetables and so on) }\end{array}$ & $5 \%$ \\
\hline
\end{tabular}

residence with a person aged 70 years or older, the person aged 70 years or older answered the questions.

In the surveys, the respondents were asked to provide demographic information including gender, number of people in the household, and annual income. The respondents were also asked to provide information pertaining to the segregation of plastic packaging waste. We classified plastic packaging waste into six categories (listed in Table 1) based on those outlined by the Japan Ministry of Environment [25]. The main reason for selecting plastic packaging waste as the fraction of MSW for study is the ease of identifying these recyclables and labeled materials. The majority of municipalities in Japan require residents to segregate their garbage in adherence with the Containers and Packaging Recycling Law of 1997. Although plastic packaging is labeled, many types of packaging (e.g., food packs, containers, bottles) make source segregation complex. The two survey questions were

(1) How frequently you segregate the six categories of plastic packaging waste on a 5-point scale? "Always," "Often," "Sometimes," "Seldom," or "Never"

(2) Do you recognize the six categories of plastic packaging waste as recyclables? "Yes" or "No"

The responses from the participants were translated into numeric values based on an assumed value assigned to each point value. Thus, frequency of segregation was translated as follows: "always $=100 \%$," "often $=75 \%$," "sometimes $=50 \%$," "seldom $=25 \%$," and "never $=0 \%$."

Ethical clearance and approval for the questionnaire survey was conducted at the Graduate School of Human Development and Environment, Kobe University.

\subsection{Quantification of Rate of Garbage Segregation}

The rate of segregation, defined as the ratio between the segregated recyclables and the total plastic packaging waste, was calculated using the following equation:

$$
S=\sum_{i=1}^{14}\left(\alpha_{i} \times w_{i}\right)
$$

The weight proportion of each type of plastic packaging waste is shown in Table 1. The segregation rate estimated using Eq. 1 was combined with the demographic information of the respondents. We also conducted a correlation analysis to assess the relationships between segregation rate and age group, lifestyle, and waste segregation behavior of the respondents.
Table 2. Demographic information (respondents aged 20-69 years)

\begin{tabular}{|c|c|c|c|c|c|}
\hline \multirow{11}{*}{$\begin{array}{l}\text { Respondent } \\
\text { age group }\end{array}$} & $20-24$ & $67(5.4 \%)$ & \multirow[t]{2}{*}{ Gender } & Male & $613(49.4 \%)$ \\
\hline & $25-29$ & $100(8.1 \%)$ & & Female & $629(50.6 \%)$ \\
\hline & $30-34$ & $107(8.6 \%)$ & \multirow{2}{*}{$\begin{array}{l}\text { Number of } \\
\text { households }\end{array}$} & Single & $238(19.2 \%)$ \\
\hline & $35-39$ & $140(11.3 \%)$ & & Multi-family & $1004(80.8 \%)$ \\
\hline & $40-44$ & $127(10.2 \%)$ & \multirow[t]{2}{*}{ Type of dwellings } & Detached house & $508(40.9 \%)$ \\
\hline & $45-49$ & $135(10.9 \%)$ & & Communal building & $734(59.1 \%)$ \\
\hline & 50-54 & $128(10.3 \%)$ & \multirow{3}{*}{$\begin{array}{l}\text { Main person who } \\
\text { brings garbage to } \\
\text { collection station }\end{array}$} & Respondent & $833(67.1 \%)$ \\
\hline & $55-59$ & $109(8.8 \%)$ & & Family & $398(32.0 \%)$ \\
\hline & $60-64$ & $168(13.5 \%)$ & & People outside home & $11(0.9 \%)$ \\
\hline & $65-69$ & $161(13.0 \%)$ & & & \\
\hline & Total & $1,242(100 \%)$ & & & \\
\hline
\end{tabular}

Table 3. Demographic information (Respondents aged 70 years or older)

\begin{tabular}{|c|c|c|c|c|c|}
\hline \multirow{9}{*}{$\begin{array}{l}\text { Respondent } \\
\text { age group }\end{array}$} & $70-74$ & $93(57.8 \%)$ & \multirow[t]{2}{*}{ Gender } & Male & $116(72.0 \%)$ \\
\hline & $75-79$ & $43(26.7 \%)$ & & Female & $45(28.0 \%)$ \\
\hline & $80-84$ & $20(12.4 \%)$ & \multirow{2}{*}{\begin{tabular}{|l|} 
Number of \\
households
\end{tabular}} & Single & $23(14.3 \%)$ \\
\hline & $85-89$ & $4(0.03 \%)$ & & Multi-family & $138(86.7 \%)$ \\
\hline & $90-94$ & $1(0.01 \%)$ & \multirow[t]{2}{*}{ Type of dwellings } & Detached house & $86(53.4 \%)$ \\
\hline & Total & $161(100 \%)$ & & Communal building & $75(46.6 \%)$ \\
\hline & & & \multirow{3}{*}{$\begin{array}{l}\text { Main person who } \\
\text { brings garbage to } \\
\text { collection station }\end{array}$} & Respondent & $106(65.8 \%)$ \\
\hline & & & & Family & $54(33.5 \%)$ \\
\hline & & & & People outside home & $1(0.06 \%)$ \\
\hline \multicolumn{6}{|c|}{ (2) Persons aged 70 years or older who lives with people } \\
\hline \multirow{8}{*}{$\begin{array}{l}\text { Respondent } \\
\text { age group }\end{array}$} & $20-69$ & $72(2.4 \%)$ & \multirow[t]{2}{*}{ Gender } & Male & $127(50.4 \%)$ \\
\hline & $70-74$ & $64(28.6 \%)$ & & Female & $125(49.6 \%)$ \\
\hline & $75-79$ & $66(25.4 \%)$ & \multirow[t]{2}{*}{ Type of dwellings } & Detached house & $153(60.7 \%)$ \\
\hline & $80-84$ & $33(26.2 \%)$ & & Communal building & $99(39.3 \%)$ \\
\hline & $85-89$ & $9(13.1 \%)$ & \multirow{3}{*}{$\begin{array}{l}\text { Main person who } \\
\text { brings garbage to } \\
\text { collection station }\end{array}$} & Respondent & $110(43.7 \%)$ \\
\hline & 90-94 & $2(0.8 \%)$ & & Family & $136(54.0 \%$ \\
\hline & 95-99 & $1(0.4 \%)$ & & People outside home & $6(2.4 \%)$ \\
\hline & Total & $252(100 \%)$ & & & \\
\hline
\end{tabular}

\section{Results}

\subsection{Questionnaire Survey}

Tables 2 and 3 show the demographic information collected using the online surveys. The majority of the respondents of each age group lived with their family. Although more than $60 \%$ of respondents brought their garbage bags to the collection station mainly themselves, respondents aged 70 years or older who lived with other people were less likely to be the main person to bring garbage bags to the collection station.

Fig. 2 shows the average frequency of segregation of each category of waste for each age group. Because there were few respondents in the 85-99 age groups, these age groups were combined into one group. Overall, the frequency of segregation was the lowest among 20-24 year old residents, but the frequency increased within the 65-69 year old group, as shown in Fig. 2(1). Multiple-family households had a higher rate of segregation than did single-family households. Young and/or single persons tended to have a low level of garbage segregation consciousness. Their level of consciousness also tended to change as the result of a life event, such as a marriage or the birth of a child. Such transitions of life events most likely affect garbage segregation behavior.

The frequency of segregation continued at a high level up to the $80-84$ year age group, as shown in Fig. 2(2). Suzuki [22] indicated that senior citizens generally can maintain their health up to approximately 75 years of age. This study revealed that senior citizens can segregate plastic packaging waste up to 


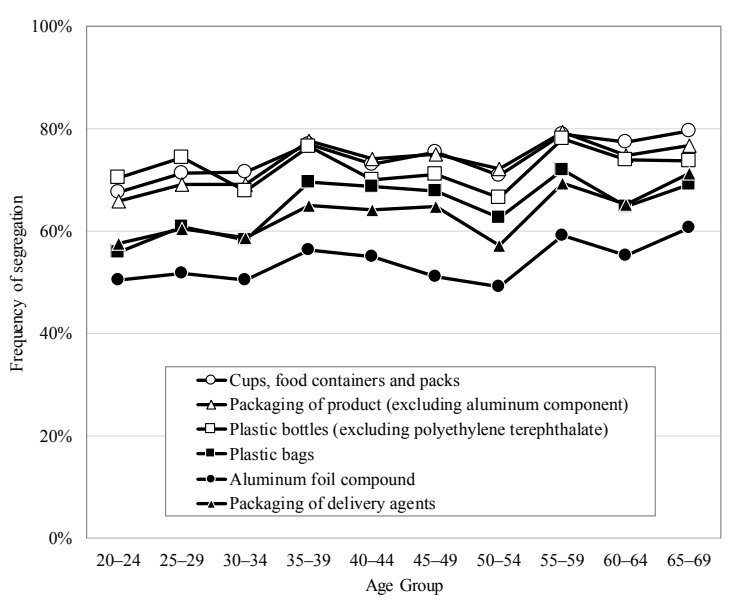

(1) 1st survey

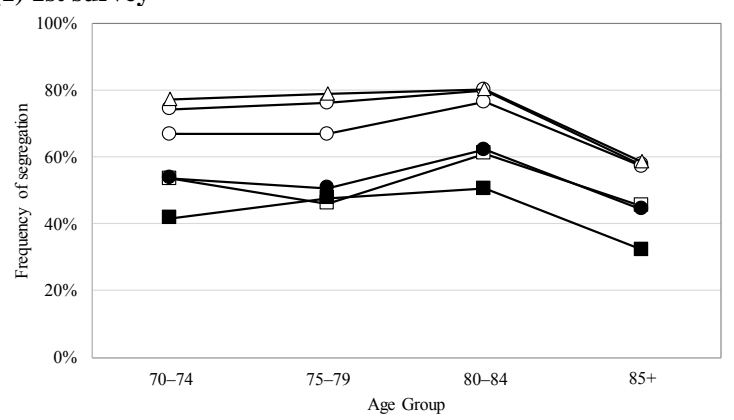

(2) 2nd survey

Fig. 2. Frequency of segregation

approximately 84 years irrespective of the decline of their mobility. In contrast, the frequency of segregation changed to have a decreasing tendency at age 85 years and older. These progressively more aged people apparently have difficulty and/or feel bothered regarding segregation.

The waste fraction "cups, food containers, and packs" had the highest segregation rate in the 65-69 year group among the 10 age groups. The fraction "aluminum foil compound" was the least segregated fraction among all age groups. This lower segregation rate can be attributed to the fact that the respondents considered cleaning these waste containers more inconvenient.

Fig. 3 shows the percentage recognition of the six categories of plastic packaging waste as a recyclable. The most recognized categories were "cups, food containers, and packs" and "packaging of product." "Plastic bottles" and "aluminum foil compound" were less recognized. Many of the respondents could identify "aluminum foil compound" as being recyclable. Although the recognition of younger people was at a higher level than that of aged people, the frequency of segregation done by aged people was higher than that by younger people, as shown in Fig. 2(1). Younger people might discard plastic packaging waste as a combustible irrespective of whether they recognize these garbage items as being recyclable. The recognition of 85 year and older people was lower compared to that of the 80-84 year old group. This decrease might contribute the decrease in frequency of segregation for this age group.

Fig. 4 shows the rate of garbage segregation by age group. The overall average rate of garbage segregation of households was $63.1 \%$. The rate of garbage segregation tended to increase from the 20-24 year group (52.0\%) to the $80-84$ year group (74.1\%); however, it tended to decrease (to $53.9 \%$ ) after 85 years and older. This suggests that older people have difficulty segregating

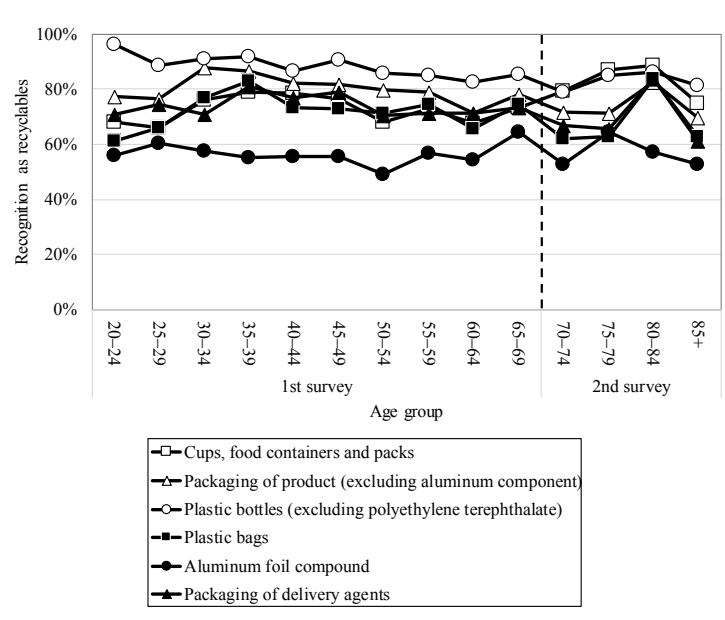

Fig. 3. Recognition of six categories of plastic packaging waste as recyclables

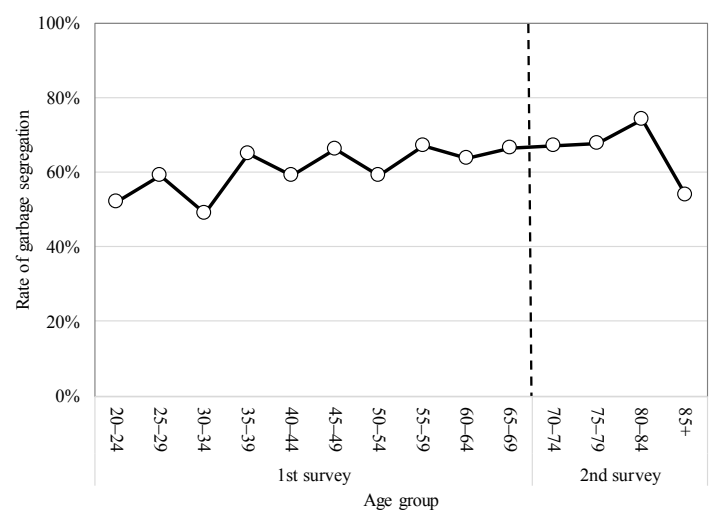

Fig. 4. Rate of garbage segregation by age group

their garbage because of a decline in their physical strength and/or cognitive function.

\section{Discussion}

This study surveyed the plastic packaging waste segregation behavior of residents of Kobe, Japan, especially aged residents. We estimated the current rate of garbage segregation using two questionnaire surveys. We found that the youngest age group had the lowest frequency of segregation despite a higher level of recognition of plastic packaging waste as being recyclable and that more aged people tended to have a higher level of plastics segregation. However, the frequency of segregation and the level of recognition decreased in the 85 year and older group. The average overall rate of garbage segregation of households was $63.1 \%$. The rate of garbage segregation tended to increase from $52.0 \%$ (20-24 years) to $74.1 \%(80-84$ years $)$; it then decreased to $53.9 \%$ for those beyond 85 years old.

The aforementioned results revealed that younger age groups have a low level of plastic waste segregation behavior despite a high level of recognition of its recyclable potential. These results suggest that education about the rules pertaining to garbage segregation is needed, particularly for younger people. Measures to facilitate garbage segregation by more aged people would also be effective. One means of education about the garbage segregation rules is the quantification of $\mathrm{CO}_{2}$ emissions avoided. Plastic wastes are energy intensive feedstock, under incineration is associated with high $\mathrm{CO}_{2}$ emission and other harmful 
compounds such as dioxins and furans particularly when Poly Vinyl Chloride (PVC) presents [26]. $\mathrm{CO}_{2}$ emission is avoided by segregating garbage that would otherwise be incinerated. For example, Fig. 5 shows the relationship between household garbage segregation and $\mathrm{CO}_{2}$ emissions from the incineration and material recovery processes. If the rate of segregation of plastic packaging waste is higher, $\mathrm{CO}_{2}$ emissions from incineration decrease. We evaluated the relationship between rate of segregation and $\mathrm{CO}_{2}$ emissions by using the life cycle assessment (LCA) methodology [1]. One reason why material recovery and incineration were focused on is that material recovery is the main stream for plastic packaging waste in Japan and incineration includes energy recovery. A lower rate of segregation results in higher $\mathrm{CO}_{2}$ emissions, and a higher rate of segregation results in lower $\mathrm{CO}_{2}$ emissions. Based on this figure, the tipping point for the rate of segregation when the $\mathrm{CO}_{2}$ emissions derived from incineration and from material recovery turn back higher is $74.0 \%$. The rate of segregation of the respondents aged 30-34 was $49.0 \%$, the lowest rate among all the age groups, and accordingly the $\mathrm{CO}_{2}$ emissions derived from the high incineration would be significant. In contrast, the highest rate of segregation was $74.1 \%$ for respondents aged 80 84. In this case, the $\mathrm{CO}_{2}$ emissions derived from incineration are in reverse proportion compared to those derived from material recovery. This result indicates the importance of moving all generations closer to the $74.1 \%$ segregation rate as a benchmark.

Showing the $\mathrm{CO}_{2}$ emissions that are not avoided is also effective for education. Fig. 6 shows the unavoided $\mathrm{CO}_{2}$ emissions of each generation calculated by using the ratio of no segregation $(=1-$ the rate of segregation). We found that the unavoided $\mathrm{CO}_{2}$ emissions from the under 39 year old group contributed to an increase in the overall unavoided $\mathrm{CO}_{2}$ emissions. This result arose because the ratio of segregation of the younger groups is lower than that of other generations. Thus, it is important to raise awareness and educate people about the impact of waste segregation.

We also considered an appropriate MSW management system for the future considering an increase in the proportion of senior citizens. Fig. 7 shows different scenarios for how changes in garbage separation could affect the MSW management system. At present, numerous citizens under 84 years of age do not experience difficulty with garbage segregation; however, they might experience such difficulty as they advance in age. This could increase the amount of plastic packaging waste that is in violation of a local municipality's segregation rules. The number of combustibles might also increase because of the reduction in garbage segregation. Thus, this could lead to an increase in the amount of garbage that is incinerated and a decrease in the amount that is recyclable (Figure 6, Scenario A). Such a scenario would lead to an increase in environmental impact in terms of $\mathrm{CO}_{2}$ emissions and treatment costs as a whole in the MSW management system compared to Scenario B. Scenario A is assumed to be the worst case scenario, and as such, it might not be realistic. However, in fact, the average life expectancy in Japan for 2015 was 83.7 years [20], and this value is expected to continue to increase. There will likely be more senior citizens in the future. Average life expectancy is also increasing for the world. Thus, problems associated with garbage segregation in Japan might also occur in other countries. The WHO [21] states that the societal response to an aging population will require a transformation of health systems away from disease-based curative models and toward the provisioning of older-personcentered and integrated care. This is similar to the situation in MSW management; precautionary measures to prevent or

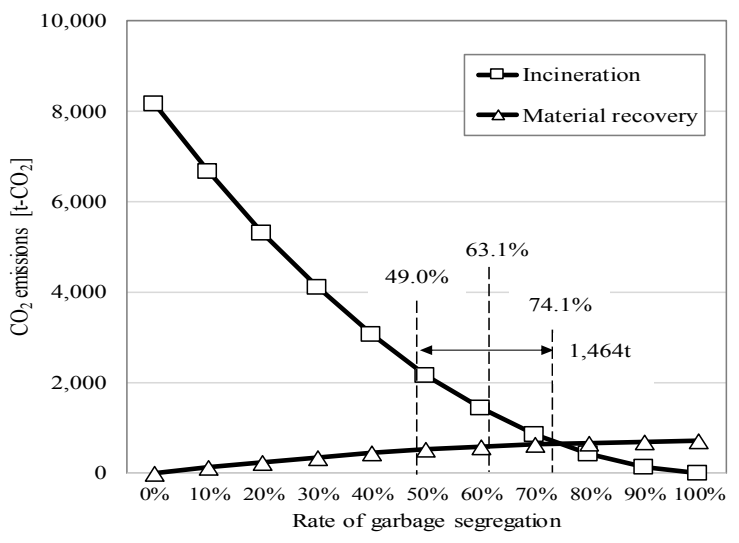

Fig. 5. Relationship between rate of garbage segregation and $\mathrm{CO}_{2}$ emissions

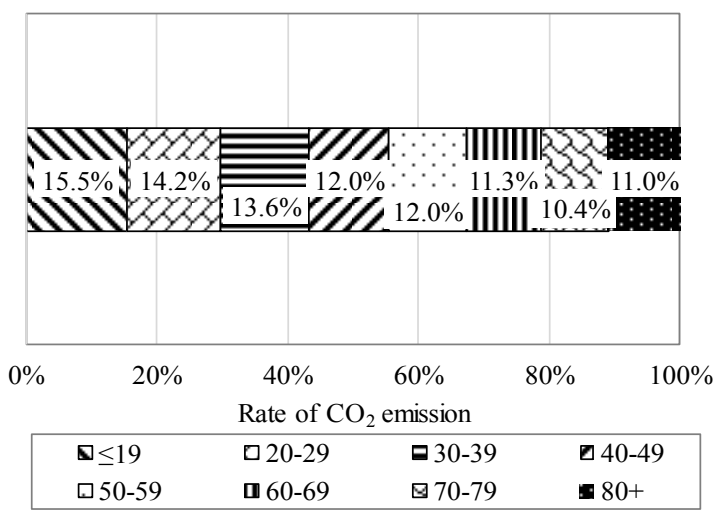

Fig. 6. Unavoided $\mathrm{CO}_{2}$ emissions by plastic packaging waste incineration.

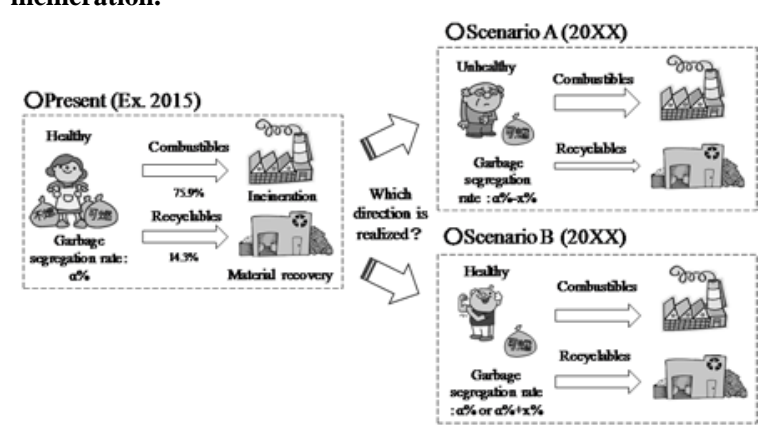

Fig. 7. Scenarios for future MSW management

minimize issues that might arise with an increase in the number of senior citizens should be discussed, beginning with a preliminary analysis of various possible future scenarios. The aforementioned results provide important insight into relevant measures useful for local municipalities affected by an increasing proportion of senior citizens. The proposed education method considering recycling and environmental burden also could be useful for municipalities attempting to enhance recycling measures.

\section{Conclusion}

As there is a projected increase number of senior residence with the population in Japan, this study undertook the influence of aged population segment on the MSW management system. Two surveys on the plastic packaging waste segregation behavior were conducted addressing the aged residents of Kobe, Japan and benchmark it against younger population segment. 
Results suggests younger age groups are less inclined into plastic waste segregation despite a high level of recognition recycling. Segregation increases among certain age (65-80 years) but decreases for advanced aged ( 85 year and older) owing to physical mobility decline. The survey suggest segregation behavior can be posted by the awareness and education of $\mathrm{CO}_{2}$ voidance. Nevertheless, the study has some limitations that remain to be solved. For example, it is important to carry out further surveys to clarify the garbage segregation behavior of senior citizens because respondents have limited ability to clarify their lifestyle and health. In addition, respondents aged 70 years or older who can operate a personal computer certainly have cognitive ability. They might also be active individuals who can segregate garbage more readily than "typical senior citizens" who do not operate a personal computer. Further surveys using methods other than the web questionnaire survey are needed for people aged 70 years or older.

\section{Nomenclature}

S Rate of segregation, point

$\mathrm{w} \quad$ Weight share of plastic packaging waste, $\%$

Greek Symbols

$\alpha \quad$ Frequency of segregation of fraction i, point

Subscripts

i Type of plastic packaging waste

\section{Acknowledgments}

This research was supported by the Mitsui Sumitomo Insurance Welfare Foundation and the JSPS KAKENHI Grant Number JP16K12687.

\section{References}

[1] T. Tabata, T. Hishinuma, T. Ihara, and Y. Genchi. Lif e cycle assessment of integrated municipal solid wast e management systems, taking account of climate cha nge and landfill shortage trade-off problems. Waste M anagement Research 2011;29:423-432, DOI:10.1177 /0734242X10379493

[2] Cabinet Office, Government of Japan, Annual Report on the Aging Society 2017, Available: www8.cao.go .jp/kourei/whitepaper/index-w.html

[3] L. Secondi, L. Principato, T Laureti. Household food waste behaviour in EU-27 countries: A multilevel ana lysis. Food Policy 2015;56:25-40, DOI: 10.1016/j.fo odpol.2015.07.007

[4] C.P. Vencatasawmy, M. Öhman, T. Brännström. A su rvey of recycling behaviour in households in Kiruna, Sweden. Waste Management Research 2000;18:545556. DOI: $10.1177 / 0734242 X 0001800605$

[5] C. Wan, G.Q. Shen, A. Yu. The role of perceived effe ctiveness of policy measures in predicting recycling $b$ ehaviour in Hong Kong. Resource, Conservation and Recycling 2014;83:141-151. DOI: 10.1016/j.resconre c. 2013.12 .009

[6] N.K.A. Malika, S.H. Abdullah, L.A. Manaf. Commun ity participation on solid waste segregation through re cycling programmes in Putrajaya. Procedia Environm ental Science 2015;30:10-14. DOI: 10.1016/j.proenv. 2015.10.002

[7] M.O. Saeed, M.N. Hassan, M.A. Mujeebu. Assessme nt of municipal solid waste generation and recyclable materials potential in Kuala Lumpur, Malaysia. Wast e Management 2009;29:2209-2213. DOI: 10.1016/j. wasman.2009.02.017

[8] S. Miafodzyeva, N. Brandt, M. Andersson. Recycling behaviour of householders living in multicultural urb an area: a case study of Järva, Stockholm, Sweden. W aste Management Research 2013;31:47-457. DOI: 10 $.1177 / 0734242 X 13476746$

[9] A. Matter, M. Dietschi, C. Zurbrügg. Improving the i nformal recycling sector through segregation of waste in the household: The case of Dhaka Bangladesh. Ha bitat International 2013;38:150-156. DOI: 10.1016/j. habitatint.2012.06.001

[10] A. Bernstad. Household food waste separation behavi or and the importance of convenience. Waste Manage ment 2014;34:1317-1323. DOI: 10.1016/j.wasman.2 014.03 .013

[11] T.L. Tudor, S.W. Barr, A.W. Gilg. Strategies for imp roving recycling behaviour within the Cornwall Natio nal Health Service (NHS) in the UK. Waste Managem ent Research 2007;25:510-516. DOI: 10.1177/07342 42X07082030

[12] Y. Matsui, M. Oosako, M. Tanaka. Effects of separat e collection policies for recyclable items on citizens' participation. J. Japan Society of Waste Management 2004;15:325-335. DOI: 10.3985/jswme.15.325 [in J apanese]

[13] R. Yanagibori, K. Koyano. A study of public opinion concerning municipal policy of sorted waste collectio $\mathrm{n}$ and waste reduction. J. Japan Society of Waste Man agement 2000;11:378-384. DOI: 10.3985/wmr.11.37 8 [in Japanese]

[14] S. Suzuki, A. Tachifuji, Y. Matsufuji, K. Yamamoto. Actual status on "station" collection point based on "l oad amount of waste set-outs" for combustible waste bag. J. Japan Society of Civil Engineering 2011;67:12 3-133. DOI: 10.2208/jscejer.67.123 [in Japanese]

[15] K. Toshiki, J. Yu. Comparative analysis of municipal solid waste management system between Japan and $\mathrm{K}$ orea. Macro Review 2015;27:1-19. DOI: 10.11286/j $\mathrm{mr} .27 .1$ [in Japanese]

[16] N. Miyamae. The relationship between the aging rate and the number of warnings in plastic waste from con tainers and wrappings in Numazu City, Shizuoka Pref ecture. University of Shizuoka, Junior College Bulleti n 2010;24:27-34. [in Japanese]

[17] M. Struk, J. Soukopová. Age structure and municipal waste generation and recycling - new challenge for th e circular economy. Proceedings of 4th International Conference on Sustainable Solid Waste Management. Limassol, Cyprus, 2016.

[18] J. Soukopová, M. Struka, J. Hřebíček. Population age structure and the cost of municipal waste collection. A case study from the Czech Republic. Journal of En vironmental Management 2017;203:655-663. DOI: 1 0.1016/j.jenvman.2016.03.030 
[19] National Institute of Population and Social Security R esearch. Population Projections for Japan-2011 to 2 060- 2012, Available: www.ipss.go.jp/site-ad/index _english/esuikei/gh2401e.asp

[20] World Health Organization. World Health Statistics 2 017, Available: apps.who.int/iris/bitstream/10665/25 5336/1/9789241565486-eng.pdf?ua $=1$

[21] World Health Organization. World Report on Ageing and Health 2015, Available: apps.who.int/iris/bitstre am/10665/186463/1/9789240694811_eng.pdf

[22] T. Suzuki. Basic knowledge for super-aging society. Kodansha 2012, pp. 34-43 [in Japanese]

[23] K. Kaiduka. Thinking the sustainable aging society. C huokeizai-sha Holdings, 2015, pp. 30-31. [in Japanes e]
[24] Hyogo Prefecture. Relevant Documents for Senior Ci tizens, Health and Welfare, 2016 Available: web.pref. hyogo.lg.jp/hw07/hw07_000000012.html [in Japanes e]

[25] Japan Ministry of Environment. Survey on Usage and Generation of Packaging Waste 2015, Available: ww w.env.go.jp/recycle/yoki/c_2_research/[in Japanese]

[26] I Janajreh, M Alshrah, S Zamzam, Mechanical recycl ing of PVC plastic waste streams from cable industry : A case study, Sustainable Cities and Society $2105 ; 1$ 8:153-160, DOI:10.1016/j.scs.2015.05.003 